\title{
Alum Mineral and the Importance for Textile Dyeing
}

\author{
Ezatollah Mozaffari* and Bijan Maleki \\ Imam khomeini international university, Qazvin, Iran
}

Submission: April 10, 2018; Published: April 25, 2018

*Corresponding author: Ezatollah Mozaffari, Imam khomeini International University, Qazvin, Iran, Tel: +9828-33901133;

Email: e.mozaffari@eng.ikiu.ac.ir

\begin{abstract}
The importance of alum as a natural mordant in textile dyeing is explained. The history of alum mineral processing was reviewed to emphasise on the heritage knowledge inherited by current trends in fashion technology and textile engineering. The review will also demonstrate the conservative environmental preservation nature of alum mineral as mordant. The need for modern evaluation of natural dyes and mordants will be highlighted.
\end{abstract}

Keywords: Alum; Mordant; Industrial heritage

\section{Introduction}

Alum was known as one of the most imperative components of textile industry before the introduction of chemical dyes in the 1850s. Its significance could be explored when studying the alum quarrying and trade in several geographical areas [1]. In literature, interesting notes on alum as a mordant for textile dyeing of yarn, cloth and leather in North America, China, Libya, Russia and Turkey could be found. In England, for instance alum was imported mainly from Papal and Spanish mines during the $16^{\text {th }}[2]$.

\section{The role of alum in textile dyeing}

It is well known that natural dyes do not readily adhere to cotton. Therefore, in order to set the color when using natural dyes alum is needed to play its role as a chemical agent which allows a reaction to occur between the dye and the fabric [3]. It may be added to the dye source to influence it; however it does not serve as a color source on its own. The fabric is impregnated with the mordant, then during the dyeing process the dye reacts with the mordant, forming a chemical bond and attaching it firmly to the fabric.

\section{A historical review of alum mineral extraction}

Abandoned mines in many areas such as those in north of Iran represent valuable industrial heritages. It is thus indispensable to review the processing stages which our predecessors were developed to extract alum from the associated gangue minerals. The alum-bearing shale was excavated and tipped over onto a bed of brushwood about $1 \mathrm{~m}$ thick and $20 \mathrm{~m}$ high. This was allowed to burn slowly for up to a year. As the calcinations reaction proceeded the clamp would shrink to half its original size. In order to extract the soluble aluminium sulphate from the calcined mass the calcined shale was barrowed to a series of stone leaching pits nearby with typical dimensions of $9 \mathrm{x}$ $4.5 \times 1.5 \mathrm{~m}$. Fresh liquid was added to the leaching tanks and the process repeated for several weeks. The waste solids were eventually dug out and discarded. The Specific gravity of the liquor from leaching rose to 1.12 , indicating 12 tons of dissolved salts to 100 of liquor [2]. At this stage the liquor contained iron and magnesium salts as well as the aluminium sulphate.

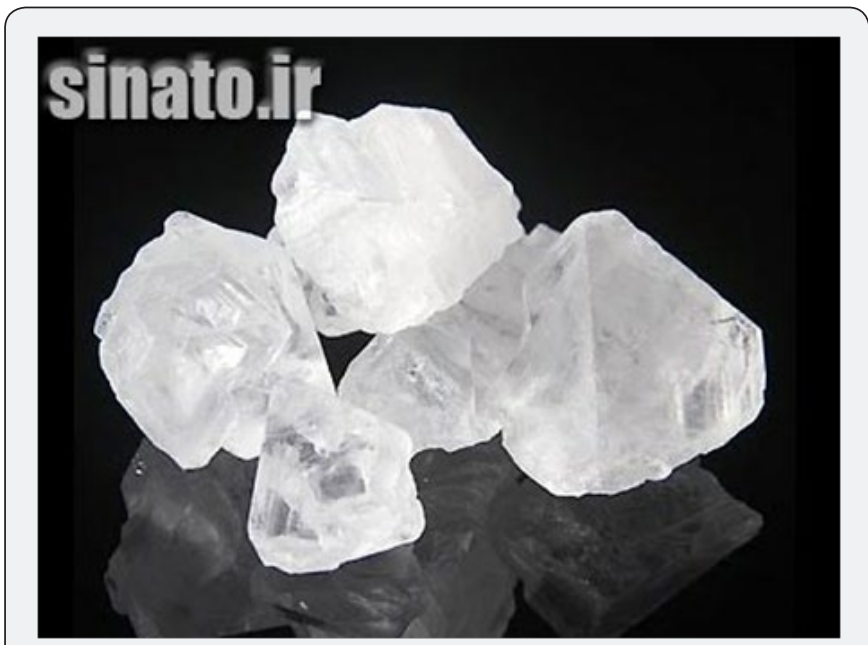

Figure 1: View of alum mineral crystals.

The next step was to clarify and concentrate the liquor, which was passed by gravity through stone channels to the Clearing House, where it was brought to the boil for twentyfour hours in open lead pans. The concentrated liquor was then passed to a lead-lined settling tank. The object of settling was to remove much of the yellow iron silicate known as «slam» and other impurities. The Formation of crude alum crystals followed 
by the recrystallization stage which took place in roaching casks which were made up of lead-lined wooden staves would resulted in a highly purified alum (Figure 1). The later stage may take another eight days.

The position of alum natural mineral extraction and preparation in the history of fashion technology may be inferred from other research outcomes, such as the one which points out that fashion has the power to tell over the years human stories and cultural changes [4].

\section{The mechanisms and color enhancement}

The aluminum metal ion in alum forms coordination complexes with dyes during the process of textile dyeing, as depicted in Figure 2.

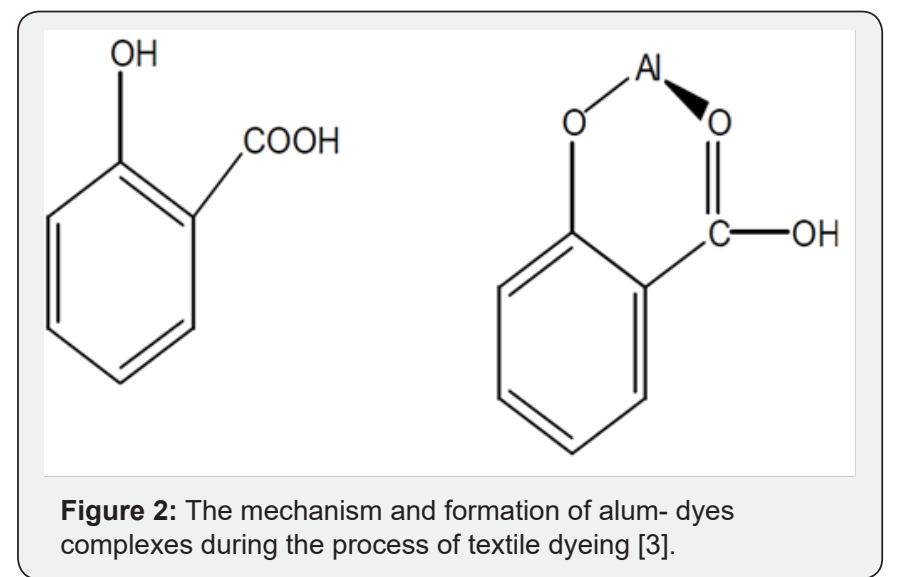

It is often remarked that the addition of a mordant to an appropriate dye solution results in a very sudden, dramatic change in color. This is due to the incorporation of the metal atom into the delocalized electron system of the dye. Metals have relatively low energy levels, so their incorporation into a delocalized system results in lowering of the overall energy. The absorbance of the hue and thus its color is related to this phenomenon.

Alum, as a natural dye is safe and non-toxic. For dyers it is imperative to ascertain whether the mordants that are used to fix the dyes are safe or not. Most of the mordants that are used for natural dyeing are not seriously toxic. Most dyers mordant the cloth and then apply the dyes as two separate steps. The advantage is that the mordant has a chance to "bite" into the fiber, so that when the color is applied, maximum amount of bonding takes place.

The role of alum is now given for mordanting cotton and wool. Cotton has very low affinity for natural dyes. Nowadays, dyers use tannins for preparing cotton so as to enable it to retain coloring matter permanently before mordanting the cotton fabric with alum.

Mordanting wool fibers with alum provides the dyer flexibility as fibers can be mordanted in advance, dried, and dyed later, or mordanted and dyed in one day. Drying and storing, or "curing" alum-mordanted fibers often results in deeper shades on wool [5].

The amount of alum to use in mordanting is important; it is recommended that alum is $12 \%$ of the weight of fiber, or 1 scant Tablespoon for 100 grams of fiber. It is also recommended to use the cream of tarter which should be $6 \%$ of the weight of fiber, or $11 / 4$ teaspoons for 100 grams of fiber. You can use alum and cream of tartar together, the cream of tartar brightens many colors and helps keep wool fibers soft [6].

Aluminum sulfate baths may be reused for multiple mordant sessions to save water and mordant. Alum may be safely disposed in a municipal water system by pouring down the drain. But it should not be disposed of in waterways or drains that flow into waterways.

Researchers at University of Nebraska - Lincoln have done investigations on wool specimens [7]. They premordantied the wool specimens with alum, chrome, copper, iron, or tin mordants and dyed with 18 yellow natural dyes. The dyed specimens were then exposed to a lamp and the color changes were evaluated instrumentally. They reported that Turmeric, fustic, and marigold dyes faded significantly more than any of the other yellow dyes [8]. However, dyes applied with tin and alum mordants faded significantly more than dyes mordanted with chrome, copper, or iron. In fact, mordant affected light fastness more than dye or length of exposure. This showed that mordant was more important than dye in predicting light fastness of colored textiles. It was recommended to make wiser decisions regarding display of a textile, museum both mordant and dye should be identified.

\section{Conclusion}

The history of alum mineral processing reflects its values as industrial heritage around geographical areas. The need for modern evaluation of natural dyes and mordants such as alum in current trends in fashion technology and textile engineering is clarified.

\section{Acknowledgement}

The authors would like to express their gratitude to Imam Khomeini International University.

\section{References}

1. Hansen V (2015) The Textile History of Whitby 1700-1914

2. (2018) The Whatmans and Wove Paper.

3. (2018) Mordanting the textiles for natural dyeing.

4. Yang S, Song Y, Tong S (2017) Fashion Industry as a Big Data Enterprise for Sustainability, Sustainability 9: 1266.

5. (2018) Wild colors.

6. (2018) How to mordant. 
7. Crews PC (1982) The Influence of Mordant on the Light fastness of Yellow Natural Dyes. Faculty Publications - Textiles, Merchandising and Fashion Design 7.
8. http://digitalcommons.unl.edu/textiles_facpub/7.

\section{Your next submission with Juniper Publishers} will reach you the below assets

- Quality Editorial service

- Swift Peer Review

- Reprints availability

- E-prints Service

- Manuscript Podcast for convenient understanding

- Global attainment for your research

- Manuscript accessibility in different formats ( Pdf, E-pub, Full Text, Audio)

- Unceasing customer service

Track the below URL for one-step submission https://juniperpublishers.com/online-submission.php 